\title{
Maternal hypothyroidism in mice influences glucose metabolism in adult offspring
}

\author{
Yasmine Kemkem ${ }^{1}$ • Daniela Nasteska ${ }^{2,3,4}$ (1) Anne de Bray ${ }^{2,3,4}$ - Paula Bargi-Souza ${ }^{5}$ - Rodrigo A. Peliciari-Garcia ${ }^{6}$. \\ Anne Guillou ${ }^{1} \cdot$ Patrice Mollard $^{1} \cdot$ David J. Hodson $^{2,3,4} \mathbb{B} \cdot$ Marie Schaeffer $^{1} \mathbb{C}$
}

Received: 20 December 2019 / Accepted: 3 April 2020 / Published online: 30 May 2020

(C) The Author(s) 2020

\begin{abstract}
Aims/hypothesis During pregnancy, maternal metabolic disease and hormonal imbalance may alter fetal beta cell development and/or proliferation, thus leading to an increased risk for developing type 2 diabetes in adulthood. Although thyroid hormones play an important role in fetal endocrine pancreas development, the impact of maternal hypothyroidism on glucose homeostasis in adult offspring remains poorly understood.

Methods We investigated this using a mouse model of hypothyroidism, induced by administration of an iodine-deficient diet supplemented with propylthiouracil during gestation.

Results Here, we show that, when fed normal chow, adult mice born to hypothyroid mothers were more glucose-tolerant due to beta cell hyperproliferation (two- to threefold increase in Ki67-positive beta cells) and increased insulin sensitivity. However, following 8 weeks of high-fat feeding, these offspring gained $20 \%$ more body weight, became profoundly hyperinsulinaemic (with a $50 \%$ increase in fasting insulin concentration), insulin-resistant and glucose-intolerant compared with controls from euthyroid mothers. Furthermore, altered glucose metabolism was maintained in a second generation of animals.

Conclusions/interpretation Therefore, gestational hypothyroidism induces long-term alterations in endocrine pancreas function, which may have implications for type 2 diabetes prevention in affected individuals.
\end{abstract}

Keywords Beta cell function $\cdot$ Calcium imaging $\cdot$ Diabetes $\cdot$ Hypothyroidism $\cdot$ Pancreas

Electronic supplementary material The online version of this article (https://doi.org/10.1007/s00125-020-05172-x) contains peer-reviewed but unedited supplementary material, which is available to authorised users.

Marie Schaeffer

Marie.Schaeffer@igf.cnrs.fr

1 Institute of Functional Genomics, CNRS, Inserm U1191, University of Montpellier, F-34094 Montpellier, France

2 Institute of Metabolism and Systems Research, University of Birmingham, Edgbaston, UK

3 COMPARE University of Birmingham and University of Nottingham, Midlands, Edgbaston, Nottingham, UK

4 Centre for Endocrinology, Diabetes and Metabolism, Birmingham Health Partners, Birmingham, UK

5 Department of Physiology and Biophysics, Institute of Biological Sciences, Federal University of Minas Gerais, Belo Horizonte, MG, Brazil

6 Morphophysiology and Pathology Sector, Department of Biological Sciences, Federal University of São Paulo, Diadema, SP, Brazil

\section{Abbreviations \\ HFD High-fat diet \\ LID Low-iodine diet \\ ND Normal diet \\ PTU Propylthiouracil}

\section{Introduction}

Type 2 diabetes and hypothyroidism are two major public health issues, affecting $\sim 9 \%$ and $2 \%$, respectively, of the population worldwide [1,2]. These endocrine pathologies alter whole body metabolism and can sometimes be related, without presenting a common aetiology [3, 4]. Type 2 diabetes arises from a complex interplay between genetic and environmental factors [5]. In particular, the fetal environment plays a key role in the establishment of a functional beta cell mass [6]. Changes in the intrauterine milieu can modify beta cell differentiation and proliferation in the fetus, leading to long-term effects on glucose metabolism [7]. 


\section{Research in context}

\section{What is already known about this subject?}

- Maternal metabolic disease and hormonal imbalance can alter fetal beta cell development, leading to increased risk for type 2 diabetes development in adulthood

- Thyroid hormones play an essential role in metabolism and fetal development

- Gestation increases demand on thyroid hormones in the mother, leading to hypothyroidism in $0.5 \%$ of pregnancies

\section{What is the key question?}

- How does maternal hypothyroidism affect glucose metabolism in mouse adult offspring?

What are the new findings?

- Maternal hypothyroidism alters glucose metabolism in offspring without modification in beta cell maturity and functional responses

- Severity of high-fat diet-induced hyperinsulinaemia and glucose intolerance is increased

- Changes in glucose metabolism are maintained in a second generation of animals

How might this impact on clinical practice in the foreseeable future?

- Gestational hypothyroidism induces transgenerational effects on glucose metabolism in the offspring, which may have implications for type 2 diabetes prevention

Different maternal conditions alter circulating concentrations of nutrients and hormones, which might impact beta cell development in utero. First, pre-existing metabolic disorders, such as malnutrition, obesity and diabetes, have been linked to increased susceptibility of the offspring to chronic diseases, such as hypertension and diabetes [7, 8]. In mice, maternal diabetes induces fetal hyperglycaemia and hyperinsulinaemia through accelerated endocrine pancreas development, predisposing to type 2 diabetes at later stages [9]. Second, gestation itself leads to important metabolic and hormonal modifications. For instance, gestational diabetes, occurring in $13 \%$ of pregnancies [10], alters endocrine pancreas maturation in the fetus and constitutes a risk factor for type 2 diabetes in adulthood [9]. In addition, gestation increases demand on thyroid hormones in the mother, leading to hypothyroidism in $0.5 \%$ of pregnancies [11].

As master metabolic gatekeepers, the thyroid hormones thyroxine (3,3',5,5' tetraiodothyronine; $\left.\mathrm{T}_{4}\right)$ and 3,3',5-triiodothyronine $\left(\mathrm{T}_{3}\right)$ play an essential role in metabolism and fetal development. Maternal hypothyroidism is associated with deficits in fetal growth and cardiac, nervous and bone maturation $[12,13]$. Such dramatic effects result from a complete dependence of the fetus on maternal thyroid hormones until mid-gestation in mice and second trimester of pregnancy in humans [14, 15], and a continued influence of maternal thyroid hormones at later stages [14]. At the level of the pancreas, different studies have demonstrated important effects of thyroid hormones on beta cell development and maturation $[16,17]$. These effects can be direct, through specific interactions with cognate receptors on beta cells [18], or indirect, through modification of the availability of growth factors [16], thereby altering glucose metabolism and insulin resistance [3]. Although a recent study showed that fetal hypothyroidism in sheep leads to increased beta cell proliferation and hyperinsulinaemia in the fetus [17], the consequences of gestational hypothyroidism on beta cell function in adult offspring remains unexplored. Thus, we sought to investigate the effects of gestational hypothyroidism on beta cell maturity and function, glucose metabolism, and susceptibility to metabolic stress such as high-fat diet (HFD) in adult mouse offspring and their descendants.

\section{Methods}

Mice Animal studies were conducted according to the European guidelines for animal welfare (2010/63/EU). Protocols were approved by the Institutional Animal Care and Use Committee (CEEA-LR-1434) and the French Ministry of Agriculture (APAFIS\#13044). Mice were housed in a conventional facility on a $12 \mathrm{~h}$ light $/ 12 \mathrm{~h}$ dark cycle and were given chow and water ad libitum. FVB/NJ mice were purchased from Janvier-SAS (Le Genest-St-Isle, France). Hypothyroidism in gestating mice was induced by feeding animals with an iodine-deficient diet (low-iodine diet, LID) supplemented with $0.15 \%$ propylthiouracil (PTU) (LID $+0.15 \%$ PTU diet TD.95125, Envigo, USA) [19] from the first day post-coitus. Offspring were subsequently fed with normal diet (ND) until age 8-10 weeks and then fed with either ND or HFD (63\% energy from fat) (Safe Diets, France) for 8 weeks. 
Analysed offspring were from at least three independent breeding pairs per group. Offspring numbers were evenly distributed between dams for analysis and allocated to treatment groups in a randomised manner to ensure that all states were represented in the different experiment arms. Second generation animals originated from two different male or three different female breeders born to two different hypothyroid mothers. The two males were each bred to three different females, and the three females each bred to one male, specifically purchased for this purpose. Experimenters were blind to group assignment during data analysis. No data were excluded unless animals died during experimentation. IPGTT, ITT and glucose-stimulated insulin secretion in vivo (GSIS) tests were as described [20,21]. We chose a glucose dose of $3 \mathrm{~g} / \mathrm{kg}$ body weight to ensure full beta cell challenge and generation of an insulin peak [22]. Mice were euthanised by decapitation after asphyxiation with $\mathrm{CO}_{2}$. Total trunk blood was collected and total $\mathrm{T}_{4}$ was measured in plasma in duplicate using a total $\mathrm{T}_{4}$ Elisa kit (EIA-1781, DRG International). $\mathrm{T}_{4}$ concentrations were measured in plasma $(50 \mu \mathrm{l})$ isolated from blood collected at the tail for a limited number of dams, to ensure proper nursing of pups. To measure $\mathrm{T}_{4}$ concentrations in neonates, pooling of blood from a minimum of four animals at day 0 postpartum (P0) was necessary for each measurement. Litters from two to three different dams, corresponding to a total of 15 to 17 P0 pups were used. A flow chart of experimental design and mouse selection for the different assays in depicted in electronic supplementary material (ESM) Fig. 1.

Confocal imaging and image analysis Pancreas preparation and antibody labelling were as described [21]. Briefly, pancreases were fixed overnight in $4 \%$ paraformaldehyde and sliced (100 $\mu \mathrm{m}$ slices) on a vibratome (Leica, Germany) before immunostaining. Antibodies used were: rabbit antiKi67 (1:200, CliniSciences, France), guinea pig anti-insulin (1:400, Abcam, UK) and mouse anti-glucagon (1:200, Sigma, USA). Nuclei were labelled using DAPI (Sigma). Images (top $20 \mu \mathrm{m}$ at the surface of slices) were acquired using a Zeiss (Germany) LSM 780 confocal microscope. Images were analysed using Imaris (Bitplane, UK), Volocity (Perkin Elmer, USA) and ImageJ (NIH, USA). For quantifications, four slices were randomly selected from at least three animals/group, and all islets present analysed. A priori, this is sufficiently-powered to detect a minimum 1.2-fold difference with an SD of $40 \%$, a power of 0.9 , and $\alpha=0.05$ (G*Power 3.1, Germany). The proportion of proliferative beta cells was obtained by dividing the number of $\mathrm{Ki} 67^{+}$nuclei by the total number of nuclei of insulin ${ }^{+}$cells in islets, as described [21]. Beta cell mass was measured by dividing the area occupied by insulin ${ }^{+}$cells by the total area of the tissue.

Islet isolation and live calcium imaging of isolated islets Islets were hand-picked after collagenase digestion of the whole pancreas [23], and cultured $\left(5 \% \mathrm{CO}_{2}, 37^{\circ} \mathrm{C}\right)$ in RPMI medium containing $10 \%$ FCS, 100 units $/ \mathrm{ml}$ penicillin, and $100 \mu \mathrm{g} / \mathrm{ml}$ streptomycin. Islets were loaded with Fluo-8 (AAT Bioquest, USA; Cat\#21082) dissolved in DMSO containing 20\% pluronic acid. Islets were then imaged using an X-Light spinning disk system (Crest, Italy) coupled to a Ti-E base (Nikon, Japan) and $\times 10 / 0.4 /$ air objective (Nikon, Japan). Excitation was delivered at $\lambda=458-482 \mathrm{~nm}$ using a Spectra X-light engine (Lumencor, USA), with emitted signals detected at $\lambda=500-550 \mathrm{~nm}$ using a Delta Evolve EM-CCD (Teledyne Photometrics, USA). Imaging buffer contained (in mmol/l) $120 \mathrm{NaCl}, 4.8 \mathrm{KCl}, 24 \mathrm{NaHCO}_{3}$, $0.5 \mathrm{Na}_{2} \mathrm{HPO}_{4}, 5$ HEPES, $2.5 \mathrm{CaCl}_{2}, 1.2 \mathrm{MgCl}_{2}$, and 3-17 Dglucose. Data were analysed using ImageJ, with traces presented as $F / F_{\min }$ where $F=$ fluorescence at any timepoint and $F_{\min }=$ minimum fluorescence. No data were excluded unless the cells displayed a clear non-physiological state (i.e. impaired viability).

Islet isolation and real-time quantitative RT-PCR Pancreatic islets were hand-picked after collagenase digestion of whole pancreas, as described [23]. Total RNA from mouse islets was extracted using RNeasy microkit (Qiagen, Germany) following the manufacturer's instructions. Reverse transcription was carried out using random hexamer oligonucleotides and SuperScriptIII Reverse Transcriptase (2000 U; Invitrogen, LifeTechnologies, USA). The reverse transcription product was diluted according to the efficiency curve and submitted in duplicates to real-time quantitative PCR using LightCycler 480 SYBR Green I Master (Roche, Switzerland) in 7500 System (Applied Biosystems, USA). Selection of housekeeping genes was performed using NormFinder software (Denmark, https:// moma.dk/normfinder-software) [24]. PCR reactions were performed following the conditions: $95^{\circ} \mathrm{C}$ for $5 \mathrm{~min}$, followed by 45 cycles of $95^{\circ} \mathrm{C}$ for $10 \mathrm{~s}$ and $72^{\circ} \mathrm{C}$ for $30 \mathrm{~s}$, and the melting curve was performed from $65^{\circ} \mathrm{C}$ up to $97^{\circ} \mathrm{C}$ for $1 \mathrm{~min}$. $C_{\mathrm{t}}$ values were recorded for each gene (listed in ESM Table 1) and normalised to the geometric mean of Ppia and Mrpl32. $C_{\mathrm{t}}$ values were then expressed relative to offspring from ND-fed animals. A list of primers used is shown in ESM Table 1.

Statistical analysis Values are represented as mean \pm SEM. Statistical tests were performed using GraphPad Prism (USA). Normality was tested using D'Agostino-Pearson test, and comparisons were made using either unpaired Student's $t$ test, or two-tailed Mann-Whitney $U$ test, as appropriate. Multiple comparisons were made using one-way or two-way ANOVA followed by Bonferroni's post hoc test. A $p$ value was considered significant at $* p<0.05, * * p<0.01, * * * p<0.001$.

\section{Results}

Maternal hypothyroidism alters glucose homeostasis in adult offspring Gestational hypothyroidism in female mice was 

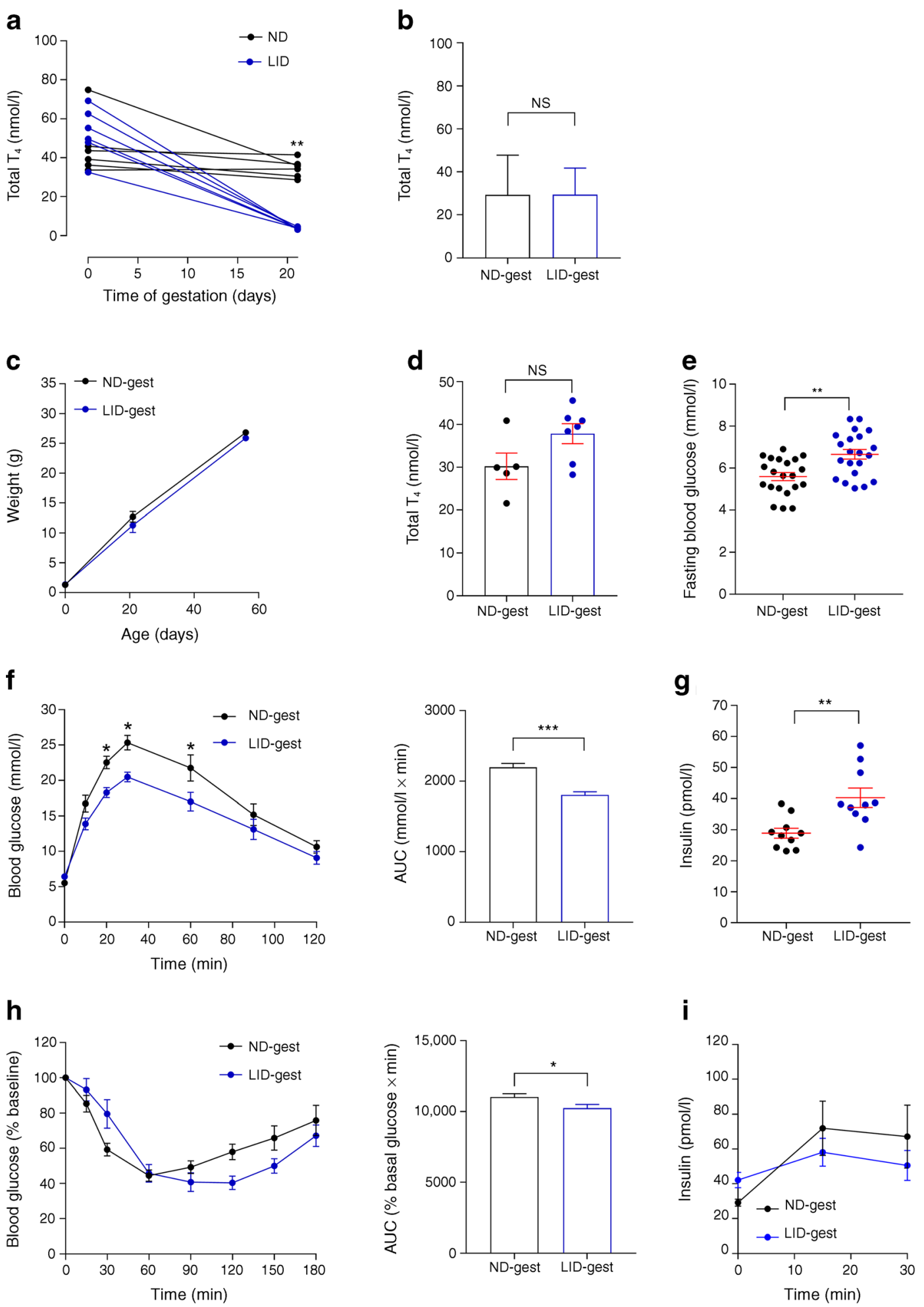

induced from the first day post-coitus by administration of an LID supplemented with PTU, known to block thyroid hormone synthesis and conversion [19]. This approach led to severe hypothyroidism, shown by a marked postpartum decrease in total $\mathrm{T}_{4}$ hormone concentrations (Fig. 1a), as previously described $[19,25,26]$. Since the model is well established, confirmation of $\mathrm{T}_{4}$ hormone concentration, which requires large amounts of plasma, was limited to a reduced number of animals to avoid stressing dams and ensure proper nursing of pups. Analysis of total $\mathrm{T}_{4}$ concentrations in pooled blood from newborn pups showed that concentrations were comparable between animals born to euthyroid and 
Fig. 1 Congenital hypothyroidism alters glucose metabolism in male offspring. (a) Total plasma $\mathrm{T}_{4}$ concentration in dams before gestation and postpartum ( $n=4-11 \mathrm{mice} /$ group, Mann-Whitney $U$ test). Statistical measurement is at 20 days for ND vs LID. (b) Measurement of total $\mathrm{T}_{4}$ in pooled blood from male and female newborn pups (at $\mathrm{P}$, pooled blood from at least four pups per measurement, 15-17 pups in total from at least two different dams in each groups, Mann-Whitney). (c-i) Adult male offspring (8-10 weeks of age) were analysed. (c) Male offspring weight over time after birth $(n=15$ mice/group, one-way ANOVA). (d) Total plasma $\mathrm{T}_{4}$ concentration in adult male offspring ( $n=5-7$ mice/group, Mann-Whitney). (e) Fasting blood glucose in adult male offspring ( $n=20$ mice/group, Mann-Whitney). (f) IPGTT using $3 \mathrm{~g}$ glucose $/ \mathrm{kg}$ body weight ( $n=10 \mathrm{mice} /$ group, two-way ANOVA) and AUC analysis ( $n=10$ mice/group, Mann-Whitney). (g) Fasting basal insulin concentrations ( $n=10 \mathrm{mice} /$ group, MannWhitney). (h) ITT $(0.75 \mathrm{U}$ insulin $/ \mathrm{kg})$ and AUC analysis $(n=10$ mice/group, Mann-Whitney). (i) In vivo insulin responses to glucose $(3 \mathrm{~g} / \mathrm{kg}),\left(n=9 \mathrm{mice} / \mathrm{group}\right.$, two-way ANOVA). $* p<0.05,{ }^{*} p<0.01$, $* * * p<0.001$ using the tests indicated above. Data are mean \pm SEM. gest, gestation

hypothyroid mothers, suggesting normal thyroid function at birth in both groups (Fig. 1b). Although male mice born to hypothyroid mothers did not display significant changes in weight gain compared with control mice (Fig. 1c) and were euthyroid (Fig. 1d), glucose metabolism in adults (810 weeks) was increased. In particular, male offspring of iodine-deficient mothers presented higher fasting blood glucose concentration (Fig. 1e) but improved glucose tolerance (Fig. 1f). Insulin sensitivity was altered (Fig. 1h), fasting insulin concentrations were increased (Fig. 1g) and glucosestimulated insulin release during IPGTT was unchanged (Fig. 1i).

In female offspring (8-10 weeks of age), alterations in glucose metabolism were also observed, albeit less pronounced (Fig. 2). Female mice born to hypothyroid mothers presented similar weight gain from birth to adulthood compared with control mice (Fig. 2a), and were euthyroid (Fig. 2b). Although fasting blood glucose concentrations were similar to those in control mice (Fig. 2c), female offspring of iodine-deficient mothers displayed improved glucose tolerance (Fig. 2d). However, insulin sensitivity (Fig. 2f), fasting insulin concentration (Fig. 2e) and glucose-stimulated insulin release (Fig. 2g) remained unchanged.

\section{Gestational hypothyroidism alters beta cell proliferation} Morphometric analyses of pancreatic sections showed that islet area was similar in offspring born to hypothyroid and euthyroid mothers (Fig. 3a-g). However, Ki67 labelling in beta cells, a marker of proliferation, was consistently found to be $\sim$ twofold higher both in males and females born to hypothyroid mothers (Fig. 3a, d, e), without changes in islet size, alpha to beta cell ratio or beta cell mass (Fig. 3b, c, f-i). Frequency distribution of islet sizes did not show a clear shift in islet sizes, since only a small increase in the percentage of very large islets in animals born to hypothyroid mothers could be evidenced (ESM Fig. 2).

Suggesting that defects in insulin secretion are distal to the triggering pathway, glucose- and $\mathrm{KCl}$-stimulated $\mathrm{Ca}^{2+}$ rises were unchanged in islets from male animals born to hypothyroid mothers (Fig. 3j-1). Furthermore, the abundance of selected genes responsible for maintenance of beta cell identity and maturity remained unchanged (Mafa, $P d x 1$, Rfx6, Pax6, Ins 1, Ins2, Slc2a2, Gck and Glp1r), with the exception of increased Nkx6.1 mRNA expression levels (Fig. 3m).

Gestational hypothyroidism renders offspring more susceptible to metabolic stress We next explored whether gestational hypothyroidism would influence compensatory responses to metabolic stress in adult male offspring. Compared with controls, animals born to hypothyroid mothers displayed increased weight gain following HFD feeding (Fig. 4a, b). However, weight gain was comparable when the same animals were fed ND for an equivalent duration (Fig. 4a, b). While HFD increased fasting glucose (Fig. 4c), and induced glucose intolerance (Fig. 4d) in all animals examined, the defect was most severe in offspring born to hypothyroid mothers, despite similar insulin sensitivity to age-matched controls (Fig. 4f). An analogous effect was seen in fasting insulin concentrations (Fig. 4e), with pronounced basal hyperinsulinaemia present in offspring born to hypothyroid mothers, despite the absence of any changes in insulin concentrations following glucose challenge (Fig. 4g). Interestingly, although maternal hypothyroidism altered glucose homeostasis in young adult offspring, differences in insulin sensitivity and glucose intolerance were not significant in older animals (16-18 weeks of age) kept on standard chow (Fig. 4). We note however that seven animals were required to reach statistical significance for female animals, so the lack of effect in male animals might reflect a sample size issue. At the morphological level, HFD increased islet size and beta cell proliferation to a similar extent in offspring from both hypothyroid and euthyroid mothers (Fig. 5a-c), as expected [27]. No differences in glucose- or $\mathrm{KCl}$-stimulated $\mathrm{Ca}^{2+}$ rises were detected between the two groups of animals (Fig. 5d-f), suggesting that altered ionic fluxes were unlikely to contribute to the impaired glucose tolerance observed in HFD-fed offspring from hypothyroid mothers.

The effects of gestational hypothyroidism on glucose homeostasis are transgenerational We finally investigated whether alterations in glucose metabolism persisted in a second generation of animals. To do this, glucose tolerance, insulin resistance, fasting insulin concentrations and beta cell proliferation were all assessed in adult offspring (8-10 weeks of age) originating from male mice born to hypothyroid mothers. While the second generation of males presented similar weight and fasting blood glucose compared with control age-matched 
a

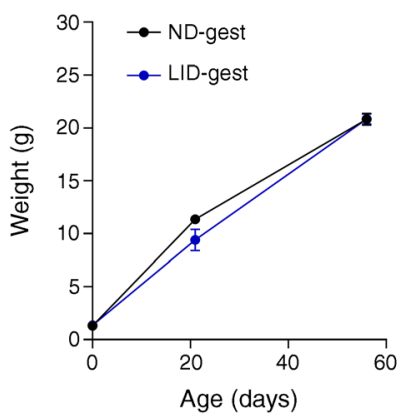

d

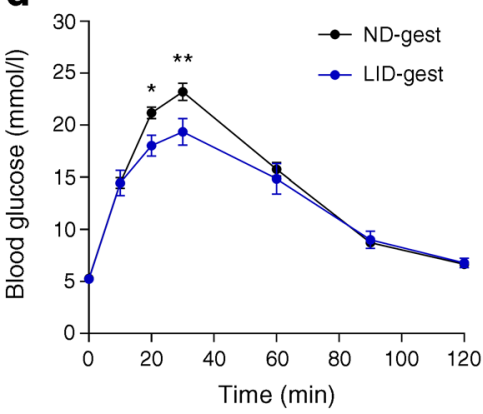

f

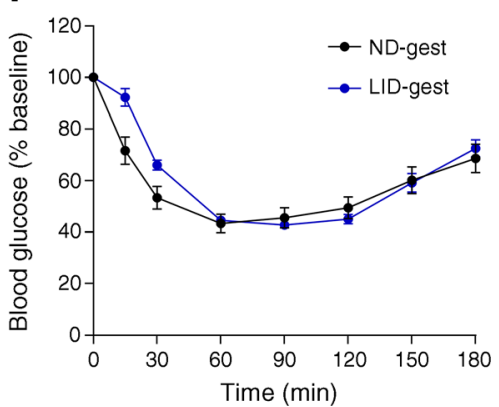

b
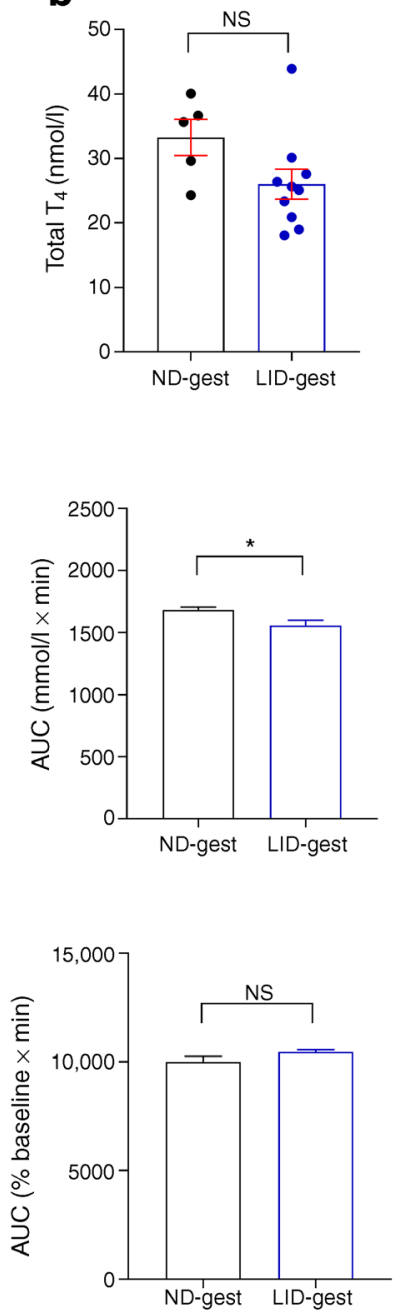

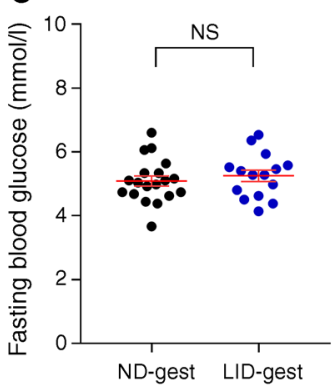

e

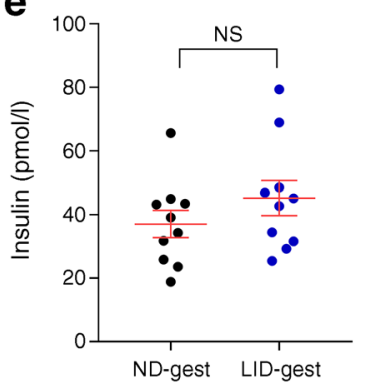

g

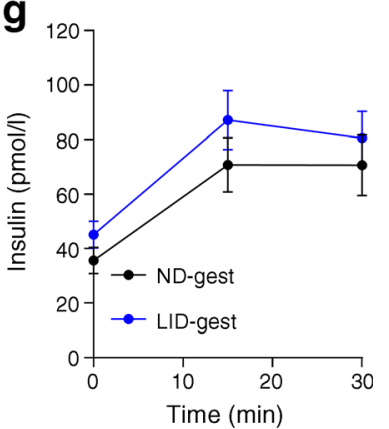

Fig. 2 Congenital hypothyroidism alters glucose metabolism in female offspring. Adult female offspring (8-10 weeks of age) were analysed. (a) Female offspring weight over time after birth $(n=15$ mice/group, oneway ANOVA). (b) Total plasma $T_{4}$ concentration in adult female offspring ( $n=5-10$ mice/group, Mann-Whitney $U$ test). (c) Fasting blood glucose in adult female offspring ( $n=15$ mice/group, MannWhitney). (d) IPGTT (3 g/kg) ( $n=10$ mice/group, two-way ANOVA)

animals (Fig. 6a, b), glucose tolerance remained improved (Fig. 6c). This change was despite normal insulin sensitivity (Fig. 6d), decreased fasting insulin concentration (Fig. 6e) and normal insulin secretion in response to intraperitoneal glucose (Fig. 6f). Second generation female offspring also presented similar weight compared with control aged-matched animals (Fig. 6g). By contrast to males, glucose tolerance was unchanged (Fig. 6i), despite increased fasting blood glucose (Fig. 6h) and decreased insulin sensitivity (Fig. 6j), decreased fasting insulin concentration (Fig. 6k) and normal glucosestimulated insulin release Fig. 61). Finally, islet size and beta cell proliferation were unchanged in both male and female offspring (Fig. $6 \mathrm{~m}-\mathrm{p}$ ). Comparable results were obtained in adult offspring (8-10 weeks of age) originating from female and AUC analysis ( $n=10$ mice/group, Mann-Whitney). (e) Fasting insulin concentrations ( $n=10 \mathrm{mice} /$ group, Mann-Whitney). (f) ITT ( $0.75 \mathrm{U} /$ $\mathrm{kg}$ ) and AUC analysis ( $n=10$ mice/group, Mann-Whitney). (g) In vivo insulin responses to glucose $(3 \mathrm{~g} / \mathrm{kg})(n=10 \mathrm{mice} / \mathrm{group}$, one-way ANOVA). $* p<0.05, * * p<0.01$ using the tests indicated above. Data are mean \pm SEM. gest, gestation

mice born to hypothyroid mothers (ESM Fig. 3). Thus, gestational hypothyroidism induces transgenerational changes in metabolism in both paternal and maternal lines, with differential effects in male and female offspring.

\section{Discussion}

Circulating factors in utero can influence fetal endocrine pancreas development and lead to life-long alterations in glucose metabolism. Since gestation modulates thyroid hormone concentrations, which are known to play an important role in beta cell development and maturation [12, 17], we sought to investigate whether maternal hypothyroidism 
a
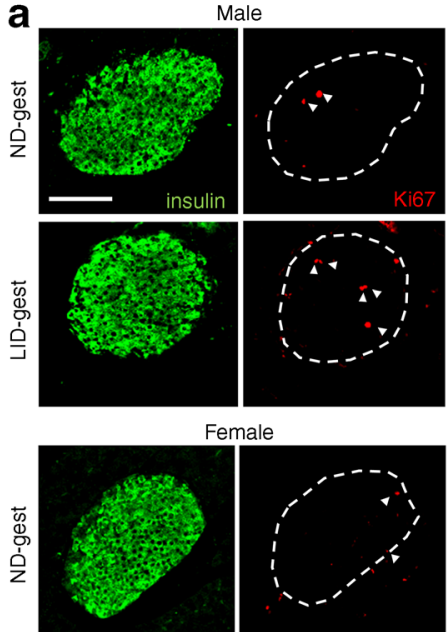

Female
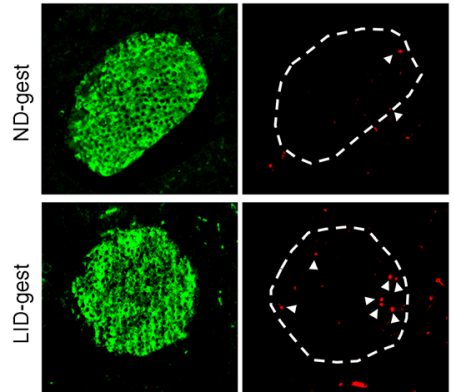

b

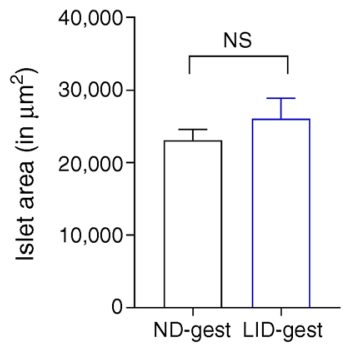

C

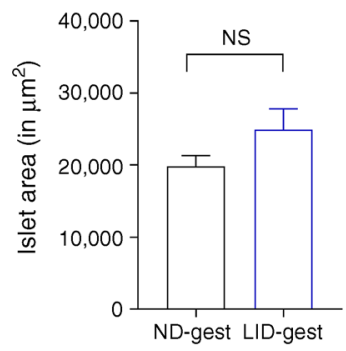

d

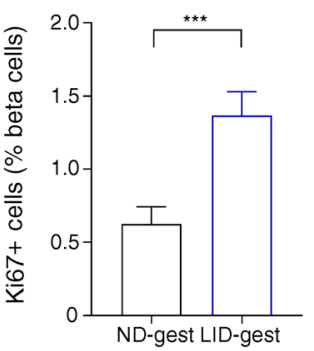

e

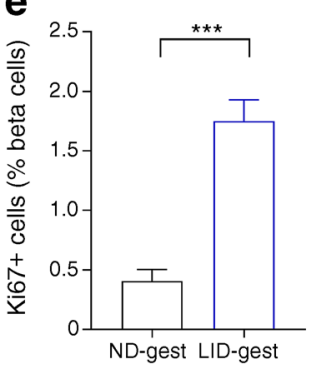

f

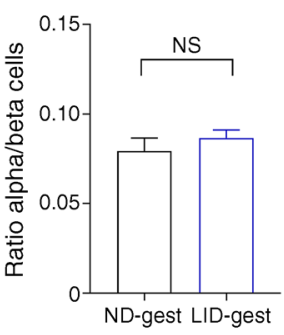

g

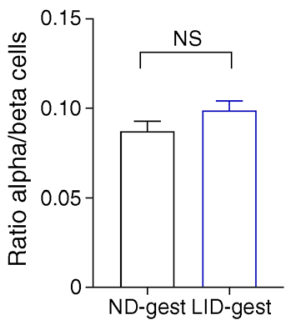

h

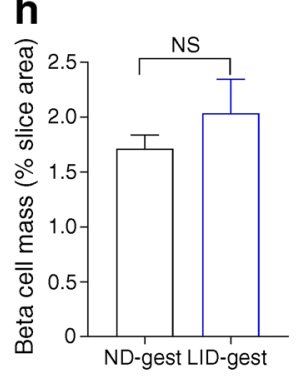

k

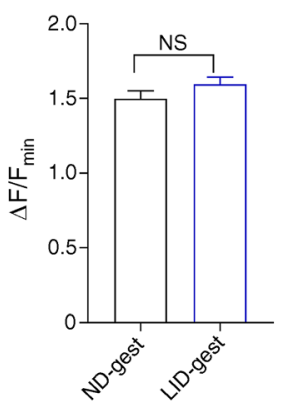

i

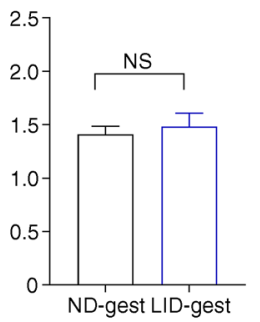

I

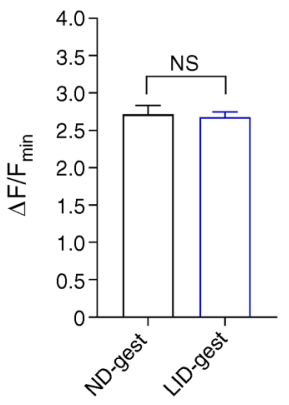

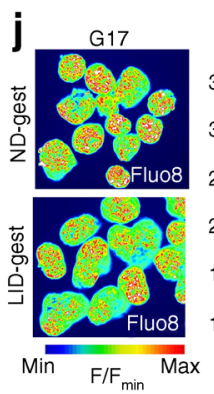
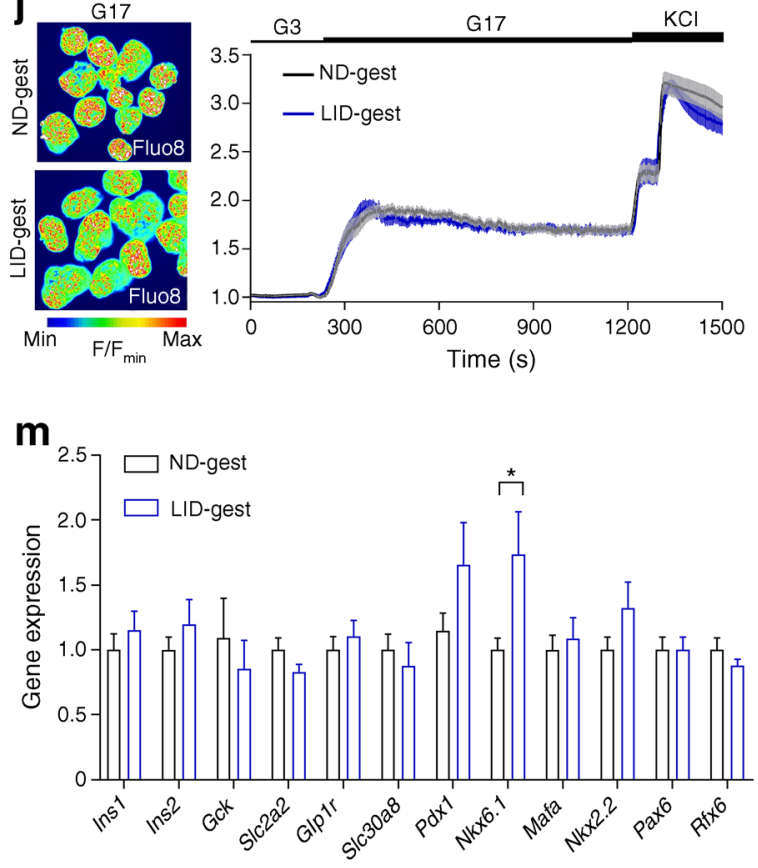

adult males (h) and females (i) ( $n=3$ mice/group, Mann-Whitney). (j-l) Representative images, with mean traces (right) and summary bar graphs $(\mathbf{k}, \mathbf{l})$ showing no changes in the amplitude of $17 \mathrm{mmol} / \mathrm{l}$ glucose- $(\mathbf{k})$ and glucose $+\mathrm{KCl}$ - (l) stimulated $\mathrm{Ca}^{2+}$ rises in LID-gest male offspring $(n=$ 44-61 islets/9-12 mice, Mann-Whitney). Note that the mean values in (j) do not correspond exactly to those in $(\mathbf{k})$, since the time to $\mathrm{Ca}^{2+}$ peak following glucose stimulation was offset by $90 \mathrm{~s}$ in a number of islets. (m) Expression profiles of key beta cell markers in islets from male offspring, measured by RT-qPCR. Data were normalised by the geometric mean of Ppia and Mrpl32. $C_{\mathrm{t}}$ values are expressed as fold increase relative to offspring from $N D$-fed control. Data are presented as mean $\pm \operatorname{SEM}(n=$ 10 mice/group, Mann-Whitney). ${ }^{*} p<0.05,{ }^{* * *} p<0.001$ using the tests indicated above. Data are mean \pm SEM. gest, gestation 

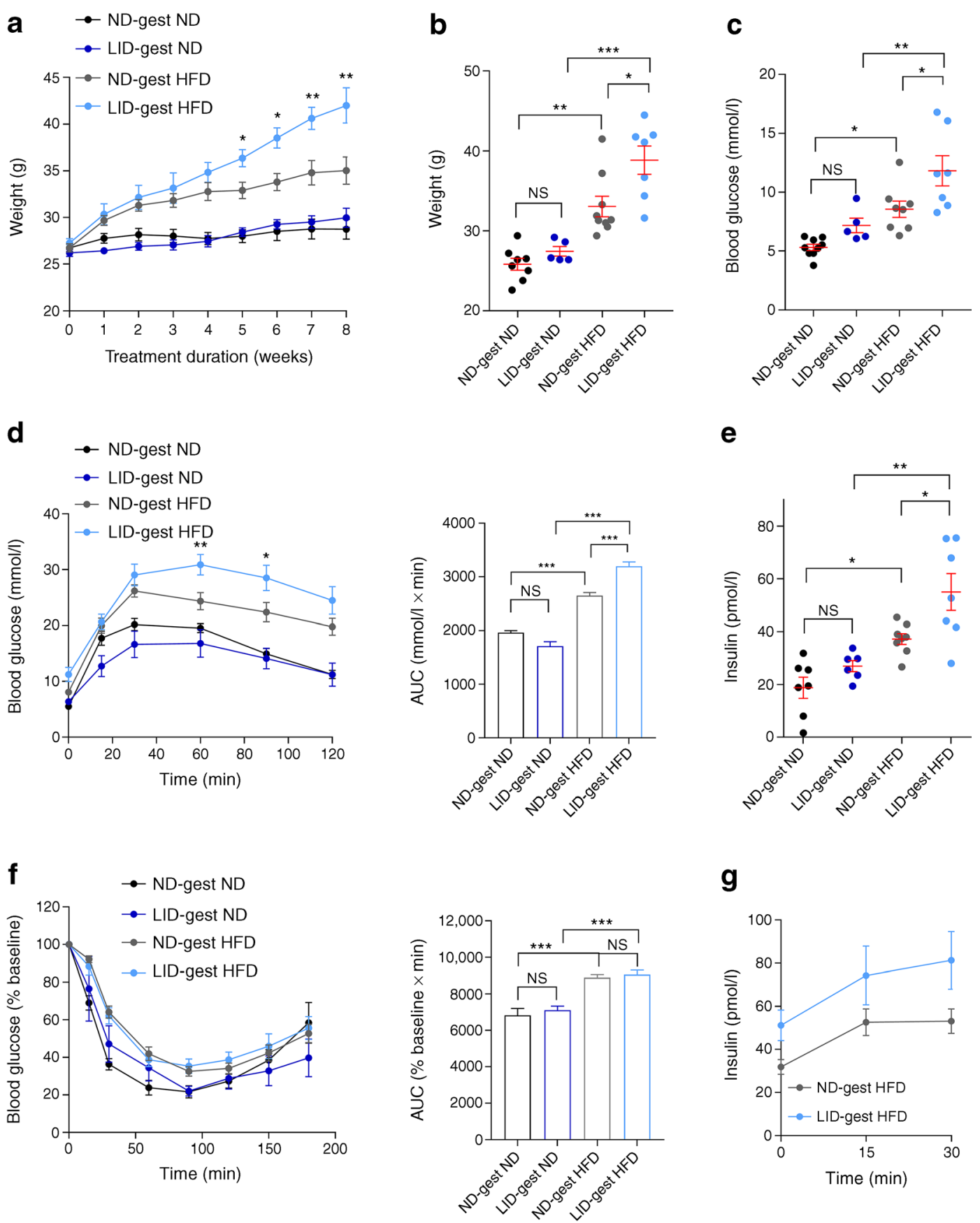

Fig. 4 Gestational hypothyroidism renders offspring more susceptible to metabolic stress. Adult male offspring (16-18 weeks of age) were analysed. (a) Growth curve post initiation of feeding treatments showing increased weight gain in male offspring from hypothyroid mothers $(n=$ 5-8 mice/group, two-way ANOVA; asterisks denote differences between LID-gest HFD and ND-gest HFD groups). (b) Animal weight at the end of feeding treatment ( 8 weeks) ( $n=5-8$ mice/group, one-way ANOVA). (c) Fasting blood glucose at the end of feeding treatment ( 8 weeks) $(n=$ 5-8 mice/group, one-way ANOVA). (d) IPGTT (3 g/kg) $(n=5-8$

influences glucose homeostasis in adult offspring. We found that gestational hypothyroidism increased beta cell proliferation, altered glucose metabolism and increased the severity of mice/group, two-way ANOVA) and AUC analysis ( $n=5-8$ mice/group, one-way ANOVA). (e) Fasting basal insulin concentrations $(n=5-8$ mice/group, one-way ANOVA). (f) ITT $(0.75 \mathrm{U} / \mathrm{kg})$ and AUC analysis ( $n=5-8 \mathrm{mice} / g r o u p$, one-way ANOVA). (g) In vivo insulin responses to glucose $(3 \mathrm{~g} / \mathrm{kg}),\left(n=8 \mathrm{mice} /\right.$ group, one-way ANOVA). ${ }^{*} p<0.05$, $* * p<0.01, * * * p<0.001$ using the tests indicated above. Data are mean \pm SEM. ND-gest ND, ND during gestation then ND; LID-gest ND, LID during gestation then ND; ND-gest HFD, ND during gestation then HFD; LID-gest HFD, LID during gestation then HFD

HFD-induced obesity in offspring, without altering beta cell maturity and functional responses. Furthermore, alterations in glucose metabolism were maintained in a second generation 
a
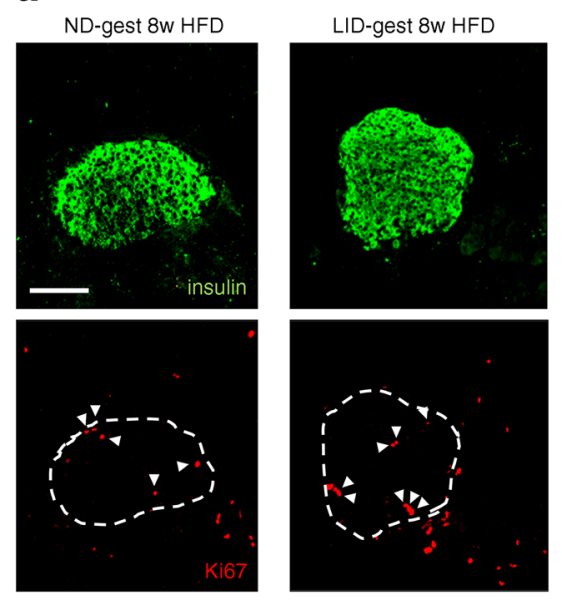

d

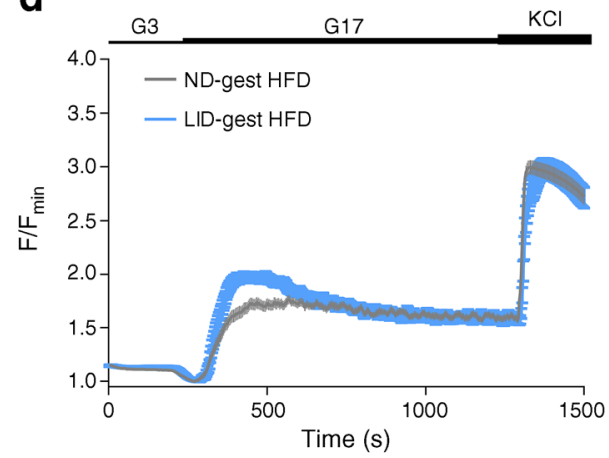

b

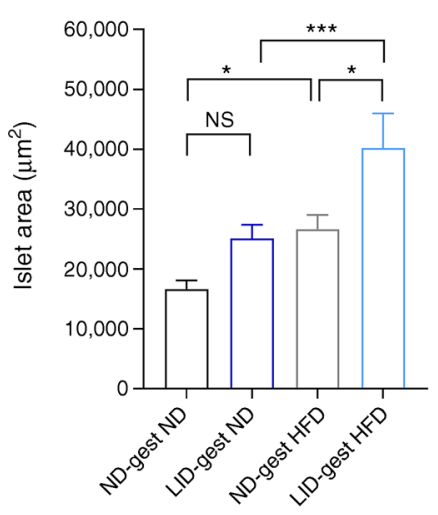

e

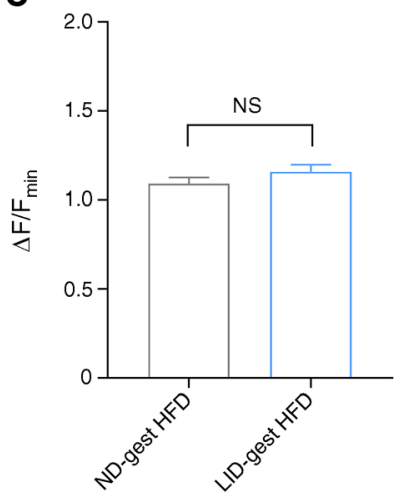

C

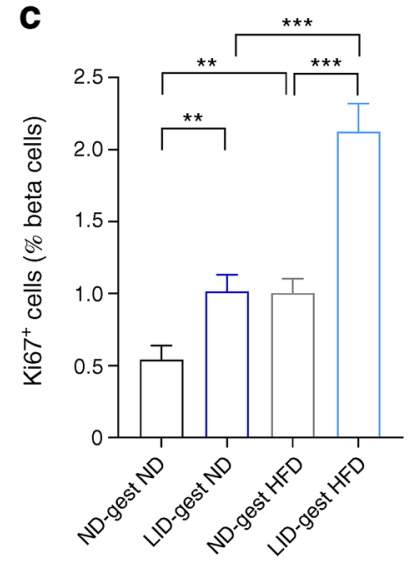

f

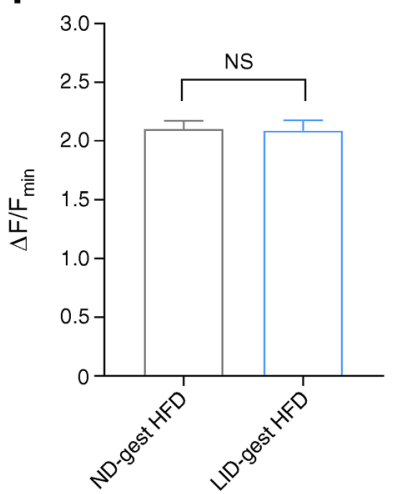

Fig. 5 Metabolic stress-induced changes in beta cell proliferation and calcium fluxes are comparable between offspring from hypothyroid and euthyroid mothers. Adult male offspring (16-18 weeks of age) were analysed. (a) Representative confocal images of pancreatic islets in male offspring (scale bar, $100 \mu \mathrm{m}, 5 \mu \mathrm{m}$ Z-projection; red, Ki67; green, insulin). Dashed circles delineate islets and arrowheads indicate $\mathrm{Ki}^{+} 7^{+}$beta cell nuclei. (b) Quantification of islet area ( $n=5-8 \mathrm{mice} /$ group, one-way ANOVA). (c) Quantification of beta cell proliferation (measured as $\%$ of beta cells positive for Ki67) ( $n=5-8 \mathrm{mice} /$ group, one-way ANOVA). (d-

of adults. These results therefore indicate that maternal hypothyroidism may exert transgenerational effects on glucose homeostasis, although primary effects on germ cells during the previous pregnancy cannot be completely excluded.

Hypothyroidism is one of the most common endocrine diseases during pregnancy and is mainly linked to dietary iodine deficiency, especially in low-middle income countries [3]. Thus, iodine deficiency in the diet constitutes a robust model to induce congenital hypothyroidism through decreases in circulating total $\mathrm{T}_{4}$ concentration during gestation [26]. While definitive confirmation of hypothyroidism would also require measurement of thyroid-stimulating hormone (TSH), commercial assay kits do not work reliably in mice. Exposure to hypothyroidism in utero has been reported to influence growth in other rodents [28, 29]. However, we could not detect significant differences in body mass between mice born to euthyroid or hypothyroid mothers. While this may reflect the model used, we note that intrauterine f) Mean traces (d) and summary bar graphs $(\mathbf{e}, \mathbf{f})$ showing no changes in the amplitude of $17 \mathrm{mmol} / 1$ glucose- (e) and glucose $+10 \mathrm{mmol} / 1 \mathrm{KCl}-(\mathbf{f})$ stimulated $\mathrm{Ca}^{2+}$ rises in LID-gest offspring fed HFD $(n=58-76$ islets/6-7 mice/group, Mann-Whitney $U$ test). $* p<0.05$, $* * p<0.01, * * * p<0.001$ using the tests indicated above. Data are mean \pm SEM. ND-gest ND, ND during gestation then ND; LID-gest ND, LID during gestation then ND; ND-gest HFD, ND during gestation then HFD; LID-gest HFD, LID during gestation then HFD

growth restriction does not necessarily correlate with altered body weights in neonates [30]. Indeed, in sheep, hypothyroidism in utero induced pancreatic beta cell proliferation and hyperinsulinaemia in the fetus [17], which would be expected to maintain growth rate.

Although the effects of thyroid hormone deficiency on fetal pancreas development were not assessed here, congenital hypothyroidism in mice altered glucose metabolism and stimulated beta cell proliferation in both adult male and female mouse offspring. This suggests impaired development of the fetal or postnatal pancreas, leading to long-term changes in glucose metabolism [31]. However, whether these long-term changes persist for the lifespan of the animal remains to be investigated. Interestingly, beta cell proliferation was not accompanied by an increase in islet size or beta cell mass or a clear shift in islet size range. This may be due to timing of analysis or relative sensitivies of beta cell proliferation vs islet 


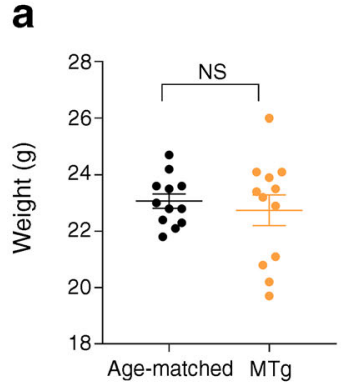

d

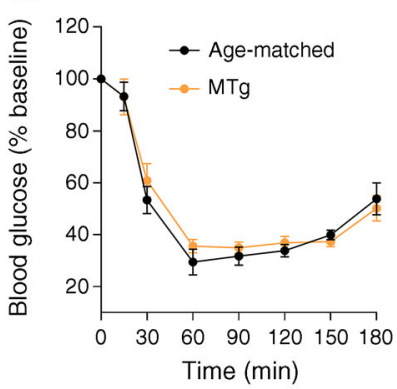

g
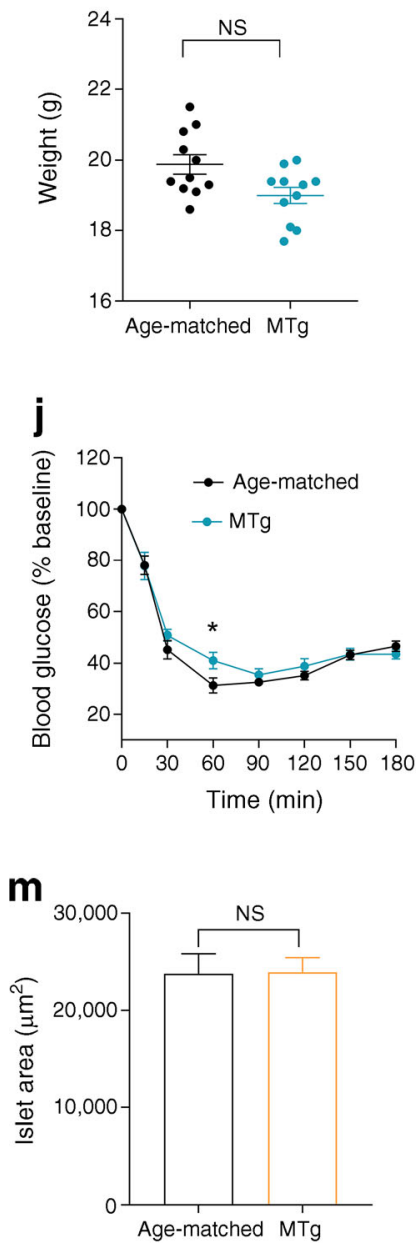
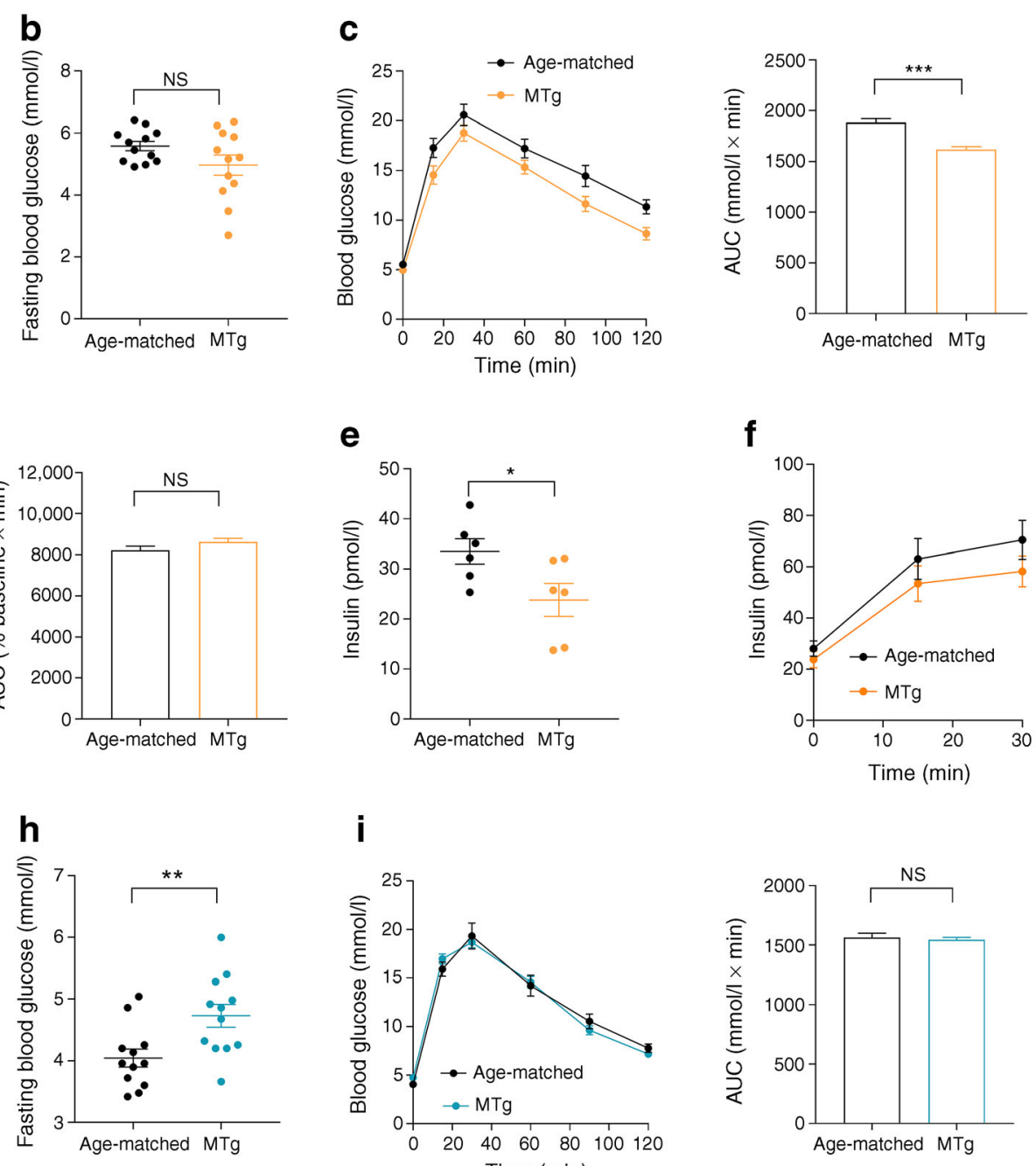

i
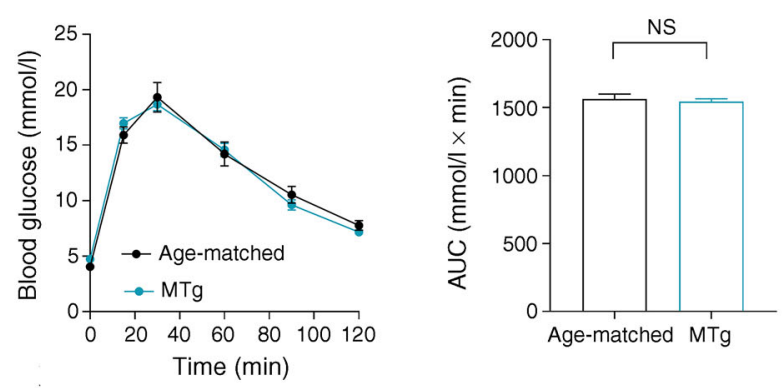

k
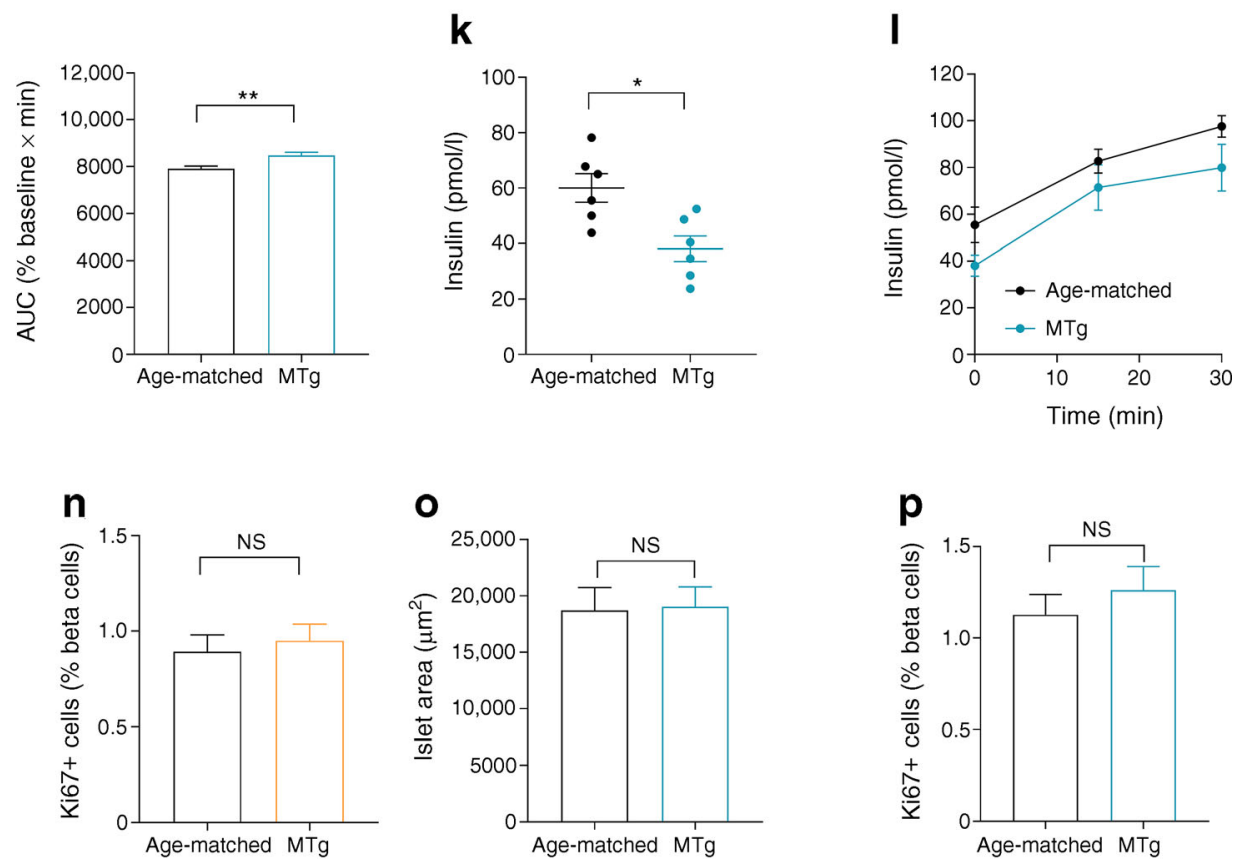

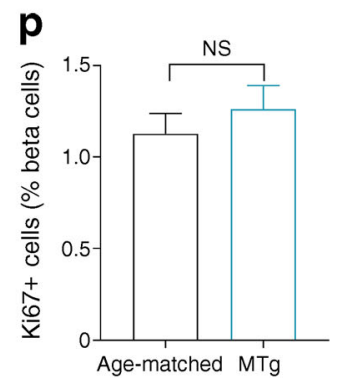


4 Fig. 6 Effects of gestational hypothyroidism on glucose homeostasis in a second generation of animals. Adult MTg mice ( $8-10$ weeks of age) were compared with age-matched controls. (a) Male weight at adult age (810 weeks) ( $n=12$ mice/group, Mann-Whitney $U$ test). (b) Fasting blood glucose in males ( $n=12 \mathrm{mice} /$ group, Mann-Whitney). (c) IPGTT in males $(3 \mathrm{~g} / \mathrm{kg})$ and AUC analysis ( $n=12$ mice/group, Mann-Whitney). (d) ITT in males $(0.75 \mathrm{U} / \mathrm{kg})$ and AUC analysis $(n=12 \mathrm{mice} /$ group, Mann-Whitney). (e) Fasting insulin concentrations in males $(n=6$ mice/group, Mann-Whitney). (f) In vivo insulin responses to glucose in males $(3 \mathrm{~g} / \mathrm{kg}),(n=6 \mathrm{mice} / \mathrm{group})$. (g) Female weight at adult age (810 weeks) ( $n=12$ mice/group, Mann-Whitney). (h) Fasting blood glucose in females ( $n=12$ mice/group, Mann-Whitney). (i) IPGTT in females $(3 \mathrm{~g} / \mathrm{kg})$ and AUC analysis $(n=12 \mathrm{mice} / \mathrm{group}$, MannWhitney). (j) ITT in females $(0.75 \mathrm{U} / \mathrm{kg})$ and AUC analysis $(n=12$ mice/group, two-way ANOVA [left] and Mann-Whitney [right]). (k) Fasting insulin concentrations in females $(n=6$ mice/group, MannWhitney). (l) In vivo insulin responses to glucose in females $(3 \mathrm{~g} / \mathrm{kg})$, ( $n=6$ mice/group). (m) Quantification of islet area in males $(n=6$ mice/group, Mann-Whitney). (n) Quantification of beta cell proliferation in males ( $n=6 \mathrm{mice} /$ group, Mann-Whitney). (o) Quantification of islet area in females ( $n=6 \mathrm{mice} /$ group, MannWhitney). (p) Quantification of beta cell proliferation in females $(n=6$ mice/group, Mann-Whitney). ${ }^{*} p<0.05, * * p<0.01, * * * p<0.001$ using the tests indicated above. Data are mean \pm SEM. MTg, second generation of male (in orange) and female (in cyan) offspring from males born to hypothyroid mothers

size measures. In addition, we cannot exclude the possibility that proliferation is balanced by apoptosis or cell cycle progression block after mitosis, maintaining beta cell mass. This, however, remains to be investigated. Overall, the alterations were more pronounced in male offspring, possibly reflecting known sex-dependent effects of fetal hypothyroidism on glucose metabolism [32] and pointing to the importance of including both sexes in studies of this type. In fact, $\mathrm{T}_{4}$-dependent liver function and metabolism is sex-dependent, and sex is an important modifier of the extent of phenotypic manifestations of hypo- or hyperthyroidism, not only at the metabolic level, but also of functional, biochemical and molecular traits [33].

In line with our results, congenital hypothyroidism has been previously shown to induce long-term alterations in glucose metabolism in adult male rat offspring [31, 34]. In particular, insulin secretion was found to be decreased, in contrast to the lack of difference detected in the present study. The reasons for this are unknown, but may include the dynamic evolution of glucose metabolism with age (young adult vs mature animals), the proliferative status of beta cells (not assessed in rat studies), and/or species-related differences.

Since glucose-stimulated $\mathrm{Ca}^{2+}$ fluxes are a major triggering signal for insulin release [35], we hypothesised that long-term alterations in glucose metabolism induced by congenital hypothyroidism may be linked to changes in beta cell stimulus-secretion coupling. Previous studies on isolated islets from male rat offspring showed that maternal hypothyroidism led to impaired insulin secretion through a combination of different mechanisms, including alteration in glycolytic pathways and ATP sensitive $\mathrm{K}^{+}\left(\mathrm{K}_{\mathrm{ATP}}\right)$ and L-type $\mathrm{Ca}^{2+}$ channel conductance [34]. However, both glucose- and $\mathrm{KCl}-$ induced $\mathrm{Ca}^{2+}$ rises were found to be unchanged in islets from male animals born to hypothyroid mothers. Thus, the changes in in vivo insulin responses and glucose metabolism described in the present study are likely to result from mechanisms distal to $\mathrm{Ca}^{2+}$ fluxes, such as amplyfying pathway (e.g. cAMP) or granule exocytosis. Alternatively, since thyroid hormones are crucial regulators of growth, development and metabolism in virtually all tissues, in particular during fetal stages [12], metabolic alterations may rise from a combination of modifications in different organs. For instance, congenital hypothyroidism has been shown to alter liver development [36], and modify glucose transporter expression, impairing glucose sensing in glucose-sensitive organs, including the liver and metabolic regions of the brain [37]. Further studies will be needed to explore both these possibilities.

In adults, beta cell proliferation is triggered in response to increased metabolic demand such as gestation and HFD feeding $[27,38]$. Although triiodothyronine stimulates proliferation of rat beta cell lines [39], whether thyroid hormones contribute to beta cell proliferation in response to demand remains unclear. During fetal development, the prepartum surge in thyroid hormone is thought to induce a switch from beta cell proliferation to functional maturation $[16,40]$, thus explaining the maintenance of beta cell proliferation in islets of hypothyroid sheep fetuses [17]. It is likely that similar mechanisms are at play in offspring of hypothyroid mothers, although we cannot exclude an increase in beta cell proliferation due to increased metabolic demand and/or insulin resistance. The source of such increased demand is, however, unclear, especially since ND-fed offspring displayed increase insulin sensitivity. Since $T_{3} / T_{4}$ are pre-requisite for cell maturation [41], and because in vivo insulin responses to glucose were decreased, we analysed overall gene expression of key markers defining adult beta cell functional identity [42]. However, we could not detect major changes in adult offspring from hypothyroid mothers, in line with the $\mathrm{Ca}^{2+}$ imaging data, suggesting that beta cell de-differentiation/or lack of maturation is not a feature here.

In addition to altered glucose metabolism and increased beta cell proliferation, maternal hypothyroidism increased susceptibility to HFD-induced metabolic stress in adult male offspring. Although glucose tolerance was not measured by dosing glucose according to lean body mass, differences are likely to persist, given the profound effect on all metabolic variables. This result fits with previous data showing that environmental alterations during endocrine pancreas development can induce long-term consequences for glucose metabolism [7]. The results here support the notion that maternal hypothyroidism may increase risk of type 2 diabetes development in later life. This increased susceptibility may be linked to exacerbated HFD-induced hyperinsulinaemia, which has previously been shown to drive insulin resistance and diet-induced obesity 
[43]. Again, changes were independent of $\mathrm{Ca}^{2+}$ channel activity, suggesting that the insulin secretory defect may lie distal to the triggering pathway. Although female offspring were not analysed, similar results would be expected, since congenital hypothyroidism also affected glucose metabolism in female offspring. Suggesting the presence of normal thyroid function in neonates born to hypothyroid mothers, total $\mathrm{T}_{4}$ concentrations were similar to control animals born to euthyroid mothers. Thus, effects of reduced maternal $\mathrm{T}_{4}$ on pancreas development might be either indirect, through altered placental size or function, for instance, or direct during early development, while the fetus is entirely dependent on maternal $\mathrm{T}_{4}$ hormone. This, however, remains to be investigated. Notably, maternal hyperglycaemia has also been shown to result in altered glucose metabolism in the progeny and increased predisposition to diabetes [44]. Since hypothyroidism affects glucose metabolism and insulin resistance [45], the extent to which alterations in maternal glucose homeostasis might account for some of the findings remains to be deciphered.

Finally, we saw that altered glucose metabolism persisted in a second generation of offspring, albeit to a lesser extent, suggesting the presence of epigenetic changes. Such changes are likely to be imprinted as a result of thyroid hormone deprivation during fetal development, since epigenetic reprogramming occurs during gametogenesis and early embryogenesis [46], before being transmitted to the next generation. It has indeed been shown in other models of nutritional insult in pregnant mice (e.g. high-fat, methyl-deficient or lowprotein diets) that induction of epigenetic marks in beta cells leads to altered function and diabetes risk later in life [47, 48]. These epigenetic changes might be in part mediated through changes in maternal thyroid hormone secretion, since nutritional status is an important regulator of thyroid activity [49]. In addition, since both liver and pancreas are affected by similar signalling pathways during development and both organs display remarkable plasticity following insult in adults, epigenetic markers are likely to affect other organs than the endocrine pancreas [50]. We concede, however, that identification of these epigenetic markers is needed, and that a multitude of other mechanisms at central and peripheral levels may also be involved in altered glucose homeostasis following changes in thyroid hormone concentrations. A multi-organ analysis is warranted to achieve a full understanding of the effects.

In summary, we show that gestational hypothyroidism induces transgenerational effects on glucose metabolism in the offspring, which may affect predisposition to type 2 diabetes development in response to metabolic stress.

Acknowledgements The authors would like to thank M. Golan, Agricultural Research Organization, Rishon Letziyon, Israel, and L. ElCheik Hussein and E. Galibert, Institute of Functional Genomics, Montpellier, France, for technical assistance, the animal facility staff (Réseau des Animaleries de Montpellier; RAM), and the MRI imaging facility, member of the France-BioImaging Infrastructure.
Data availability The datasets generated during and/or analysed during the current study are available from the corresponding author on reasonable request.

Funding Authors were supported by grants from the Agence Nationale de la Recherche (ANR BETA-DYN JCJC13 to MS, France-BioImaging ANR-10-INBS-04 and ANR Peripulse to PM), Inserm, CNRS, University of Montpellier and Région Languedoc-Roussillon. YK was supported by a Project Support Grant from the British Society for Neuroendocrinology. PB-S was supported by a São Paulo Research Foundation (FAPESP 2016/24941-7) Fellowship. DJH was supported by a Diabetes UK R.D. Lawrence (12/0004431) Fellowship, a Wellcome Trust Institutional Support Award, MRC Confidence in Concept, MRC (MR/N00275X/1 and MR/S025618/1) Project and Diabetes UK (17/0005681) Project Grants. This project has received funding from the European Research Council (ERC) under the European Union's Horizon 2020 research and innovation programme (Starting Grant 715884 to DJH).

Authors' relationships and activities The authors declare that there are no relationships or activities that might bias, or be perceived to bias, their work.

Contribution statement MS and DJH conceived and designed experiments; YK, DN, ADB, PB-S, AG and MS performed experiments; YK, DN, ADB, PBS, RAP-G, PM, DJH and MS analysed data; DJH and MS wrote the manuscript. All authors revised critically the manuscript and provided their final approval of the version to be published. MS is the guarantor of this work.

Open Access This article is licensed under a Creative Commons Attribution 4.0 International License, which permits use, sharing, adaptation, distribution and reproduction in any medium or format, as long as you give appropriate credit to the original author(s) and the source, provide a link to the Creative Commons licence, and indicate if changes were made. The images or other third party material in this article are included in the article's Creative Commons licence, unless indicated otherwise in a credit line to the material. If material is not included in the article's Creative Commons licence and your intended use is not permitted by statutory regulation or exceeds the permitted use, you will need to obtain permission directly from the copyright holder. To view a copy of this licence, visit http://creativecommons.org/licenses/by/4.0/.

\section{References}

1. Taylor PN, Albrecht D, Scholz A et al (2018) Global epidemiology of hyperthyroidism and hypothyroidism. Nat Rev Endocrinol 14(5):301-316. https://doi.org/10.1038/nrendo.2018.18

2. Cho NH, Shaw JE, Karuranga S et al (2018) IDF Diabetes Atlas: global estimates of diabetes prevalence for 2017 and projections for 2045. Diabetes Res Clin Pract 138:271-281. https://doi.org/10. 1016/j.diabres.2018.02.023

3. Duntas LH, Orgiazzi J, Brabant G (2011) The interface between thyroid and diabetes mellitus. Clin Endocrinol 75(1):1-9. https:// doi.org/10.1111/j.1365-2265.2011.04029.x

4. Panveloski-Costa AC, Serrano-Nascimento C, Bargi-Souza P, Poyares LL, Viana G d S, Nunes MT (2018) Beneficial effects of thyroid hormone on adipose inflammation and insulin sensitivity of obese Wistar rats. Physiol Rep 6(3):e13550. https://doi.org/10. 14814/phy2.13550

5. Gaulton KJ, Ferreira T, Lee Y et al (2015) Genetic fine mapping and genomic annotation defines causal mechanisms at type 2 diabetes susceptibility loci. Nat Genet 47(12):1415-1425. https://doi.org/ 10.1038/ng.3437 
6. Bouwens L, Rooman I (2005) Regulation of pancreatic beta-cell mass. Physiol Rev 85(4):1255-1270. https://doi.org/10.1152/ physrev.00025.2004

7. Portha B, Chavey A, Movassat J (2011) Early-life origins of type 2 diabetes: fetal programming of the beta-cell mass. Exp Diabetes Res 2011:1-16. https://doi.org/10.1155/2011/105076

8. Chavey A, Ah Kioon MD, Bailbé D, Movassat J, Portha B (2014) Maternal diabetes, programming of beta-cell disorders and intergenerational risk of type 2 diabetes. Diabetes Metab 40(5):323330. https://doi.org/10.1016/j.diabet.2014.02.003

9. Bernard C, Della Zuana O, Ktorza A (2013) Interaction entre facteurs d'environnement et fonds génétique dans le diabète de type 2: L'apport des modèles animaux. Medecine/Sciences 29(8-9): 791-799. https://doi.org/10.1051/medsci/2013298020 [article in French]

10. Melchior H, Kurch-Bek D, Mund M (2017) The prevalence of gestational diabetes. Dtsch Arztebl Int 114(24):412-418. https:// doi.org/10.3238/arztebl.2017.0412

11. Lazarus J, Brown RS, Daumerie C, Hubalewska-Dydejczyk A, Negro R, Vaidya B (2014) 2014 European thyroid association guidelines for the management of subclinical hypothyroidism in pregnancy and in children. Eur Thyroid J 3(2):76-94. https://doi. org/10.1159/000362597

12. Forhead AJ, Fowden AL (2014) Thyroid hormones in fetal growth and prepartum maturation. J Endocrinol 221(3):R87-R103. https:// doi.org/10.1530/JOE-14-0025

13. Bonet B, Herrera E (1991) Maternal hypothyroidism during the first half of gestation compromises normal catabolic adaptations of late gestation in the rat. Endocrinology 129(1):210-216. https://doi.org/ 10.1210/endo-129-1-210

14. Polak M (2014) Human fetal thyroid function. Endocr Dev 26:1725. https://doi.org/10.1159/000363152

15. de Escobar GM, Obregón MJ, Escobar del Rey F (2004) Maternal thyroid hormones early in pregnancy and fetal brain development. Best Pract Res Clin Endocrinol Metab 18(2):225-248. https://doi. org/10.1016/j.beem.2004.03.012

16. Aguayo-Mazzucato C, Zavacki AM, Marinelarena A et al (2013) Thyroid hormone promotes postnatal rat pancreatic $\beta$-cell development and glucose-responsive insulin secretion through MAFA. Diabetes 62(5):1569-1580. https://doi.org/10.2337/db12-0849

17. Harris SE, De Blasio MJ, Davis MA et al (2017) Hypothyroidism in utero stimulates pancreatic beta cell proliferation and hyperinsulinaemia in the ovine fetus during late gestation. $\mathrm{J}$ Physiol 595(11):3331-3343. https://doi.org/10.1113/JP273555

18. Aïello V, Moreno-Asso A, Servitja JM, Martín M (2014) Thyroid hormones promote endocrine differentiation at expenses of exocrine tissue. Exp Cell Res 322(2):236-248. https://doi.org/10. 1016/j.yexcr.2014.01.030

19. Costa-e-Sousa RH, Astapova I, Ye F, Wondisford FE, Hollenberg AN (2012) The thyroid axis is regulated by NCoR1 via its actions in the pituitary. Endocrinology 153(10):5049-5057. https://doi.org/ 10.1210/en.2012-1504

20. Gupta D, Jetton TL, LaRock K et al (2017) Temporal characterization of $\beta$-cell adaptive and maladaptive mechanisms during chronic high fat feeding in C57BL/6NTac mice. J Biol Chem 292(30): 12449-12459. https://doi.org/10.1074/jbc.M117.781047

21. Michau A, Hodson DJ, Fontanaud P et al (2016) Metabolism regulates exposure of pancreatic islets to circulating molecules in vivo. Diabetes 65(February):463-475. https://doi.org/10.2337/db151168

22. Yang JK, Lu J, Yuan SS et al (2018) From hyper- to hypoinsulinemia and diabetes: effect of KCNH6 on insulin secretion. Cell Rep 25(13):3800-3810. https://doi.org/10.1016/j.celrep. 2018.12.005

23. Szot GL, Koudria P, Bluestone JA (2007) Murine pancreatic islet isolation. J Vis $\operatorname{Exp}(7): 255$. https://doi.org/10.3791/255
24. Andersen CL, Jensen JL, Ørntoft TF (2004) Normalization of realtime quantitative reverse transcription-PCR data: a model-based variance estimation approach to identify genes suited for normalization, applied to bladder and colon cancer data sets. Cancer Res 64(15):5245-5250. https://doi.org/10.1158/0008-5472.CAN-040496

25. Castinetti F, Brinkmeier ML, Gordon DF et al (2011) PITX2 and PITX1 regulate thyrotroph function and response to hypothyroidism. Mol Endocrinol 25(11):1950-1960. https://doi.org/10.1210/ me.2010-0388

26. Ghanbari M, Ghasemi A (2017) Maternal hypothyroidism: an overview of current experimental models. Life Sci 187:1-8. https://doi. org/10.1016/j.lfs.2017.08.012

27. Mosser RE, Maulis MF, Moullé VS et al (2015) High fat dietinduced beta cell proliferation occurs prior to insulin resistance in C57Bl/6J male mice. Am J Physiol Endocrinol Metab 308(7): E573-E582. https://doi.org/10.1152/ajpendo.00460.2014

28. Özgür E, Özgür BG, Aksu H, Cesur G (2016) The effect of congenital and postnatal hypothyroidism on depression-like behaviors in juvenile rats. J Clin Res Pediatr Endocrinol 8(4):439-444. https:// doi.org/10.4274/jcrpe.3498

29. Amano I, Takatsuru Y, Khairinisa MA, Kokubo M, Haijima A, Koibuchi N (2018) Effects of mild perinatal hypothyroidism on cognitive function of adult male offspring. Endocrinology 159(4): 1910-1921. https://doi.org/10.1210/en.2017-03125

30. Haugaard CT, Bauer MK (2001) Rodent models of intrauterine growth restriction. Scand J Lab Anim Sci 28(1):10-22

31. Farahani H, Ghasemi A, Roghani M, Zahediasl S (2010) The effect of maternal hypothyroidism on the carbohydrate metabolism and insulin secretion of isolated islets in adult male offspring of rats. Horm Metab Res 42(11):792-797. https://doi.org/10.1055/s-00301262826

32. Bagheripuor F, Ghanbari M, Zahediasl S, Ghasemi A (2015) Comparison of the effects of fetal hypothyroidism on glucose tolerance in male and female rat offspring. J Physiol Sci 65(2):179-185. https://doi.org/10.1007/s12576-015-0358-7

33. Rakov H, Engels K, Hönes GS et al (2016) Sex-specific phenotypes of hyperthyroidism and hypothyroidism in mice. Biol Sex Differ 7(1):36. https://doi.org/10.1186/s13293-016-0089-3

34. Karbalaei N, Ghasemi A, Hedayati M, Godini A, Zahediasl S (2014) The possible mechanisms by which maternal hypothyroidism impairs insulin secretion in adult male offspring in rats. Exp Physiol 99(4):701-714. https://doi.org/10.1113/expphysiol.2013. 073825

35. Hodson DJ, Mitchell RK, Bellomo EA et al (2013) Lipotoxicity disrupts incretin-regulated human $\beta$ cell connectivity. J Clin Invest 123(10):4182-4194. https://doi.org/10.1172/JCI68459

36. Pickard MR, Leonard AJ, Ogilvie LM et al (2003) Maternal hypothyroidism in the rat influences placental and liver glycogen stores: fetal growth retardation near term is unrelated to maternal and placental glucose metabolic compromise. J Endocrinol 176(2): 247-255. https://doi.org/10.1677/joe.0.1760247

37. Gholami H, Jeddi S, Zadeh-Vakili A et al (2017) Transient congenital hypothyroidism alters gene expression of glucose transporters and impairs glucose sensing apparatus in young and aged offspring rats. Cell Physiol Biochem 43(6):2338-2352. https://doi.org/10. $1159 / 000484386$

38. Sorenson RL, Brelje TC (1997) Adaptation of islets of Langerhans to pregnancy: $\beta$-cell growth, enhanced insulin secretion and the role of lactogenic hormones. Horm Metab Res 29(6):301-307. https:// doi.org/10.1055/s-2007-979040

39. Furuya F, Shimura H, Yamashita S, Endo T, Kobayashi T (2010) Liganded thyroid hormone receptor- $\alpha$ enhances proliferation of pancreatic $\beta$-cells. J Biol Chem 285(32):24477-24486. https:// doi.org/10.1074/jbc.M109.100222 
40. Aguayo-Mazzucato C, Dilenno A, Hollister-Lock J et al (2015) MAFA and $\mathrm{T}_{3}$ drive maturation of both fetal human islets and insulin-producing cells differentiated from hESC. J Clin Endocrinol Metab 100(10):3651-3659. https://doi.org/10.1210/jc. 2015-2632

41. Puri S, Roy N, Russ HA et al (2018) Replication confers $\beta$ cell immaturity. Nat Commun 9(1):485. https://doi.org/10.1038/ s41467-018-02939-0

42. Rutter GA, Pullen TJ, Hodson DJ, Martinez-Sanchez A (2015) Pancreatic $\beta$-cell identity, glucose sensing and the control of insulin secretion. Biochem J 466(2):203-218. https://doi.org/10.1042/ BJ20141384

43. Mehran AE, Templeman NM, Brigidi GS et al (2012) Hyperinsulinemia drives diet-induced obesity independently of brain insulin production. Cell Metab 16(6):723-737. https://doi. org/10.1016/j.cmet.2012.10.019

44. Kahraman S, Dirice E, De Jesus DF, Hu J, Kulkarni RN (2014) Maternal insulin resistance and transient hyperglycemia impact the metabolic and endocrine phenotypes of offspring. Am J Physiol Endocrinol Metab 307(10):E906-E918. https://doi.org/10.1152/ ajpendo.00210.2014

45. Xu C, Zhou L, Wu K et al (2019) Abnormal glucose metabolism and insulin resistance are induced via the IRE1 $\alpha / \mathrm{XBP}-1$ pathway in subclinical hypothyroidism. Front Endocrinol 10:303. https://doi. org $/ 10.3389 /$ fendo. 2019.00303

46. Cantone I, Fisher AG (2013) Epigenetic programming and reprogramming during development. Nat Struct Mol Biol 20(3): 282-289. https://doi.org/10.1038/nsmb.2489

47. Xie R, Carrano AC, Sander M (2015) A systems view of epigenetic networks regulating pancreas development and $\beta$-cell function. Wiley Interdiscip Rev Syst Biol Med 7(1):1-11. https://doi.org/ $10.1002 /$ wsbm. 1287

48. Zhu Z, Cao F, Li X (2019) Epigenetic programming and fetal metabolic programming. Front Endocrinol (Lausanne) 10:764. https:// doi.org/10.3389/fendo.2019.00764

49. Pałkowska-Goździk E, Lachowicz K, Rosołowska-Huszcz D (2017) Effects of dietary protein on thyroid axis activity. Nutrients 10(1):5

50. Fernandez-Barrena MG, Pin CL (2016) Chromatin remodeling and epigenetic reprogramming in chronic disease and cancer in the liver and pancreas. In: Binda O, Fernandez-Zapico ME (eds) Chromatin signaling and diseases. Academic Press, Cambridge MA, pp 365385. https://doi.org/10.1016/B978-0-12-802389-1.00020-4

Publisher's note Springer Nature remains neutral with regard to jurisdictional claims in published maps and institutional affiliations. 